\title{
Numerical simulations of high reactivity gasoline fuel sprays under vaporizing and reactive conditions
}

\author{
Balaji Mohan, Mohammed Jaasim Mubarak Ali, Ahfaz Ahmed, and Francisco Hernandez Perez \\ King Abdullah University of Science \& Technology \\ Jaeheon Sim \\ Saudi Aramco \\ William Roberts, Mani Sarathy, and Hong Im \\ King Abdullah University of Science \& Technology
}

\begin{abstract}
Gasoline compression ignition (GCI) engines are becoming more popular alternative for conventional spark engines to harvest the advantage of high volatility. Recent experimental study demonstrated that high reactivity gasoline fuel can be operated in a conventional mixing controlled combustion mode producing lower soot emissions than that of diesel fuel under similar efficiency and NOx level [1]. Therefore, there is much interest in using gasoline-like fuels in compression ignition engines. In order to improve the fidelity of simulation-based GCI combustion system development, it is mandatory to enhance the prediction of spray combustion of gasoline-like fuels. The purpose of this study is to model the spray characteristics of high reactivity gasoline fuels and validate the models with experimental results obtained through an optically accessible constant volume vessel under vaporizing [2] and reactive conditions [3]. For reacting cases, a comparison of PRF and KAUST multi-component surrogate (KMCS) mechanism was done to obtain good agreement with the experimental ignition delay. From this study, some recommendations were proposed for GCI combustion modelling framework using gasoline like fuels.
\end{abstract}

\section{Introduction}

Spray combustion depends highly on effective liquid fuel atomization, which controls the fuel evaporation rate and air-fuel mixing, and in turn dictates the emission levels and brake power of the engine [4]. Poor fuel atomization leads to non-uniform fuel-air mixing. Local inhomogeneity in the mixture composition can result in varied ignition and emission characteristics [5]. The fuel injection and spray break-up process are complex in nature, which involves turbulent and time-dependent two-phase flow. Consequently, modelling the spray phenomena is a challenging task, especially with the advent of new complex fuels.

Gasoline compression ignition (GCI) engines are becoming popular to exploit the advantage of higher fuel volatility and potentially lower aromatic content [1]. The development of GCI to low-temperature partially premixed compression ignition (PPCI) strategy can help in obtaining a better $\mathrm{NO}_{\mathrm{x}}$-soot trade-off. Therefore, there is much interest in using gasoline-like fuels in compression ignition engines. Naphtha being a high reactivity gasoline fuel is one of the candidate fuels for advanced combustion engines [6,7].

Page 1 of 8
To improve the fidelity of simulation-based GCI combustion system development, it is mandatory to enhance the prediction of spray characteristics of gasoline-like fuels, especially naphtha fuel. The purpose of this study is to model the spray characteristics of high reactive gasoline fuel and validate the models with experimental results obtained through an optically accessible constant volume vessel under vaporizing and reactive conditions by Zhang et al. [2] and Meng et al. [3].

\section{Experimental conditions and fuel specification}

The spray experiments were performed in an optically accessible constant volume chamber ta Michigan Technological University (MTU). The chamber is a pre-burn type which combusts a gaseous mixture of acetylene and hydrogen to generate appropriate ambient conditions prior to the injection of fuel. The fuel injection event takes place during the combustion chamber cool down phase when exact ambient condition was reached. Further details of the experimental facilities can be found in Zhang et al. [2] and Meng et al. [3]. The nozzle used was a convergent single hole nozzle. The specifications of the injector are shown in table 1 . The experimental initial and boundary conditions are listed in table 2 .

Table 1. Fuel injector specifications

\begin{tabular}{|l|l|}
\hline Description & $\begin{array}{l}\text { Single hole solenoid driven } \\
\text { hydraulically lifted needle }\end{array}$ \\
\hline Outlet diameter $\left(D_{\text {out }}\right)[\mu \mathrm{m}]$ & 176 \\
\hline K-factor & 1.8 \\
\hline$C_{d}(\operatorname{Re} \sim 12000)$ & 0.94 \\
\hline
\end{tabular}

Table 2. Experimental initial and boundary conditions

\begin{tabular}{|l|l|}
\hline Injection pressure [MPa] & $100-150-200$ \\
\hline Injection duration [ms] & $>=3.0$ \\
\hline Ambient temperature [K] & $800-1200$ \\
\hline Ambient pressure [MPa] & $3-6-10$ \\
\hline Ambient Oxygen [\%] & 0,15 \\
\hline
\end{tabular}


The fuel used is high reactivity gasoline. The Research Octane Number (RON) of the fuel is 58.8 which is lower than typical gasoline (RON 91). It has an equivalent Cetane Number (CN) of 33.7. This high reactivity gasoline has lower cetane number and contains less aromatics and high volatile in nature compared to that of diesel fuel. The properties of the fuel used in this study is shown in table 3 in comparison to that commercial diesel and gasoline (RON 91).

Table 3. Fuel properties

\begin{tabular}{|l|l|l|l|}
\hline Fuel & $\begin{array}{l}\text { High reactivity } \\
\text { gasoline }\end{array}$ & Diesel & $\begin{array}{l}\text { Commercial } \\
\text { gasoline }\end{array}$ \\
\hline RON & 58.8 & - & 91.4 \\
\hline MON & 57.9 & - & 84.6 \\
\hline AKI & 58.4 & - & 88.0 \\
\hline CN & 33.7 & 43.7 & 20.4 \\
\hline Density $\left[\mathrm{kg} / \mathrm{m}^{3}\right]$ & 705 & 841 & 733 \\
\hline Kinematic viscosity $\left[\mathrm{mm}^{2} / \mathrm{s}\right]$ & 0.58 & 2.25 & 0.55 \\
\hline H/C ratio & 2.124 & 1.834 & 1.854 \\
\hline Aromatics $[\%$ vol.] & 9.1 & 29.7 & 25.7 \\
\hline Olefins $[\%$ vol.] & 0.4 & 29.7 & 10.4 \\
\hline Sulfur $[\mathrm{ppm}]$ & 19.3 & 11.9 & 3.0 \\
\hline IBP $\left[{ }^{0} \mathrm{C}\right]$ & 32.3 & 176 & 34 \\
\hline $10 \%\left[{ }^{0} \mathrm{C}\right]$ & 58.2 & 206 & 51 \\
\hline $50 \%\left[{ }^{0} \mathrm{C}\right]$ & 94.4 & 249 & 83 \\
\hline $90 \%\left[{ }^{0} \mathrm{C}\right]$ & 124.0 & 303 & 151 \\
\hline FBP $\left[{ }^{0} \mathrm{C}\right]$ & 139.7 & 337 & 198 \\
\hline Net Heat Value $[\mathrm{MJ} / \mathrm{kg}]$ & 43.363 & 42.818 & 43.42 \\
\hline & & & \\
\hline
\end{tabular}

\section{Numerical methodology}

Fuel spray and combustion simulations were performed using a Eulerian-Lagrangian approach in the commercial CFD code CONVERGE. It incorporates various models for spray injection, atomization, break-up, turbulence, droplet collision, coalescence and evaporation. For turbulence modeling, the RANS-based renormalization group (RNG) $k-\varepsilon$ model was used. These equations are solved by using a finite volume solver. The spray break-up was modeled using the modified Kelvin-Helmholtz Rayleigh-Taylor (KHRT) model without an ad hoc break-up length.

The computational domain is a cylinder of $100 \mathrm{~mm}$ in diameter and $100 \mathrm{~mm}$ in height. CONVERGE generates the computational grid during runtime. The base grid size is fixed at $2 \mathrm{~mm}$. To resolve the near-nozzle spray development process in detail, a fixed embedding is employed such that the minimum grid size is $0.25 \mathrm{~mm}$. In addition to fixed embedding, three levels of adaptive mesh refinement (AMR) were employed for the velocity field. Figure 1 shows the mesh generated by CONVERGE with fixed embedding and AMR over the base grid at $0.5 \mathrm{~ms}$ after the start of injection (ASOI).

In the simulations, the fuel liquid properties were generated from Aspen HYSYS [8]. This has been extensively validated in previous studies [1,9]. The fuel liquid properties of high reactivity gasoline used in this simulation are shown in fig. 2 in comparison with that of the properties of diesel and gasoline fuels from CONVERGE database.

Page 2 of 8
The viscosities of liquids decrease with increasing temperature either under isobaric conditions or as saturated liquids. The temperature dependence is more pronounced and nearly exponential. From fig. 2, it can be observed that high reactivity gasoline is the less viscous fuel among the three fuels compared. Thermal conductivity usually decreases with increase in temperature similar to liquid viscosities. However, unlike viscosity, temperature dependence of thermal conductivity is weak and nearly linear. Among the three fuels, high reactivity gasoline is the less conductive fuel. In general, the liquids tend to expand when their temperature increases. Therefore, increasing temperature decreases density. It is interesting to note that the density of high reactivity gasoline is close to gasoline fuel between $200-500 \mathrm{~K}$. Latent heat of vaporization is the difference between the enthalpy of the saturated vapor and that of the saturated liquid at the same temperature. Many experimental values of heat of vaporization show that it is related to the slope of the vapor pressuretemperature curve [10]. Therefore, the heat of vaporization of high reactivity gasoline is high compared to that of diesel and gasoline because of its high vapor pressure. Liquid specific heat capacities are not strong functions of temperature. In fact, a minimum is often observed at temperatures slightly below the normal boiling point. At high temperatures, specific heat values are large and strong functions of temperature, approaching infinity at the critical point [10]. This trend is observed for all the fuels compared. As the temperature is raised, the surface tension of a liquid in equilibrium with its own vapor decreases and becomes zero at the critical point. It is important to note that the surface tension of high reactivity gasoline fuel is very close to that of the gasoline fuel. Vapor pressure of liquid is the equilibrium pressure of a vapor above its liquid, that is the pressure of the vapor resulting from evaporation of a liquid. As the temperature of a liquid increases its vapor pressure also increases. This is because at a higher temperature, more molecules have enough energy to escape from the liquid and exerts higher pressure above the liquid. It can be noted that high reactivity gasoline has higher vapor pressure among the three fuels. This is due to lower boiling point of high reactivity gasoline compared to that of the diesel and gasoline fuels.

Two different mechanism were used in this study 1) PRF mechanism by An et al. $[11,12]$ and 2) reduced KAUST Multi-Component Surrogate (KMCS) mechanism. The PRF mechanism consists of 80 species and 204 reactions. The new KMCS mechanism was reduced from detailed mechanism by Sarathy et al. [13] using CHEMKIN-Pro with tolerance of $2 \%$. The new reduced KMCS mechanism consists of 111 species and 456 reactions. The composition of high reactivity gasoline multi-component surrogate is given in table 4 .

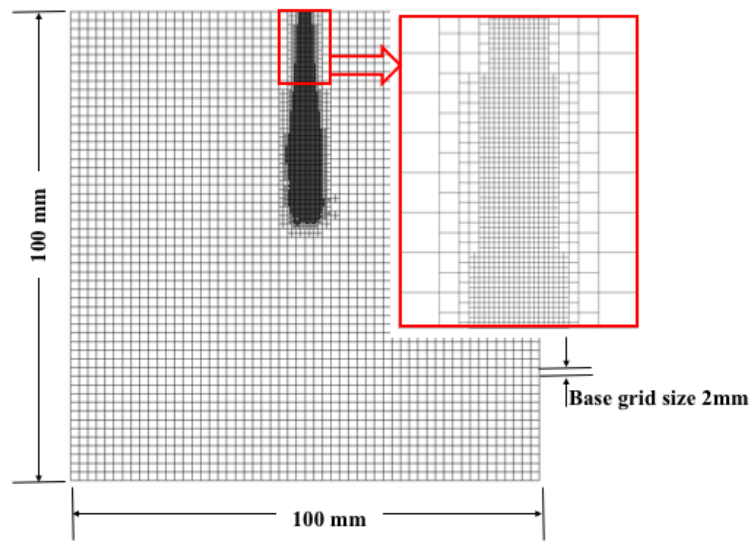

Figure 1. Grid generated by CONVERGE at $0.5 \mathrm{~ms}$ ASOI. 


\section{Results and discussion}

Table 4. Composition of high reactivity gasoline multi-component surrogate

\begin{tabular}{|l|l|l|}
\hline Species & Chemical formula & $\begin{array}{l}\text { Mole } \\
\text { fraction }\end{array}$ \\
\hline N-Pentane & $\mathrm{C}_{5} \mathrm{H}_{12}$ & 0.14 \\
\hline N-Heptane & $\mathrm{C}_{7} \mathrm{H}_{16}$ & 0.24 \\
\hline iso-Octane & $\mathrm{C}_{8} \mathrm{H}_{18}$ & 0.21 \\
\hline Toluene & $\mathrm{C}_{7} \mathrm{H}_{8}$ & 0.11 \\
\hline Cyclopentane & $\mathrm{C}_{5} \mathrm{H}_{10}$ & 0.09 \\
\hline 2-methylhexane & $\mathrm{C}_{7} \mathrm{H}_{16}$ & 0.20 \\
\hline
\end{tabular}
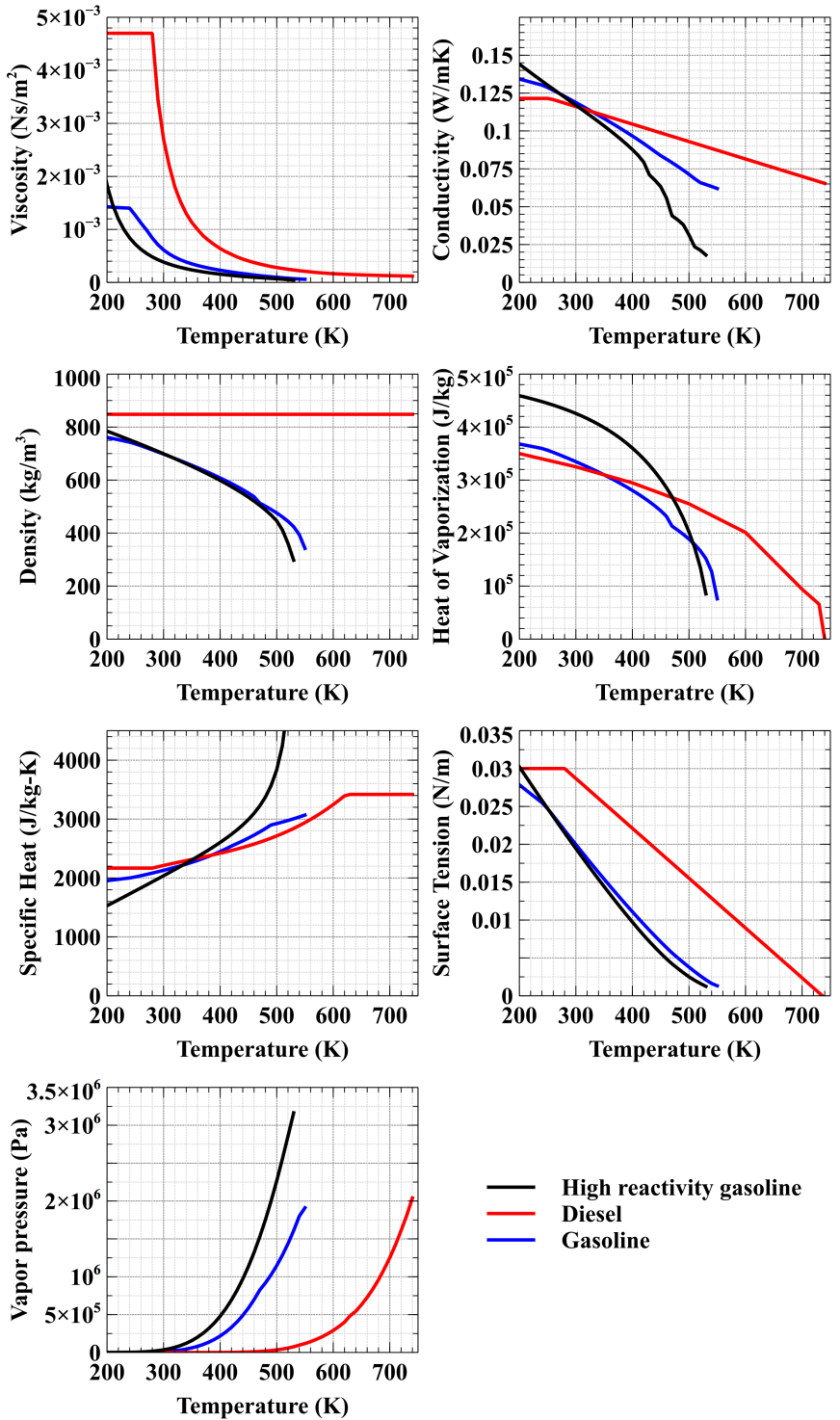

Figure 2. Liquid properties of high reactivity gasoline generated from Aspen HYSYS, diesel and gasoline properties from CONVERGE.
Liquid penetration and vapor penetration are used for validation. Liquid penetration is defined as the axial location encompassing $95 \%$ of the injected mass at that instant of time. Vapor penetration is defined as the farthest downstream location of $0.01 \%$ fuel mass fraction contour at that instant. For validation purposes, the liquid and vapor penetration measurements of high reactivity gasoline fuel at injection pressure of $150 \mathrm{MPa}$, ambient pressure of $3 \mathrm{MPa}$ and ambient temperature of $1000 \mathrm{~K}$ were employed.

\section{Effect of spray angle}

To study the effect of spray angle on the liquid and vapor penetrations, average experimental spray angle and experimental spray angle over time were given as input. The experimental spray angle was given as input using a lookup table. Figure 3 shows the experimental spray angle over time and time-averaged value calculated from the experiment. Figure 4 shows the effect of different spray angle inputs on liquid and vapor penetration of high reactivity gasoline fuel. The transient spray angle input over time using a lookup table gives better predictions than just using a single timeaveraged spray angle. It should also be noted that initial over prediction of liquid length is overcome by using transient spray angle. Therefore, using more detailed experimental values for spray angle improves fidelity of the simulation results.

\section{Effect of KH-RT model constant}

Three values of the KH time constant $\mathrm{B}_{1}$, were chosen. They are the default value of 7 , larger value of 10 and smaller value of 5 .

Similarly, three values of RT break-up model size constant, $C_{R T}$, were chosen. They are the default value of 0.1 , and two larger values of 0.5 and 1.0. Vapor and liquid penetration of high reactivity gasoline fuel with these different constants are shown in Figure 5 and 6. Fig. 5 shows that the liquid penetration is affected by the KH time constant $\mathrm{B}_{1}$, but vapor penetration shows a negligible change. Both liquid and vapor penetration show a negligible change with RT model size constant as shown in fig. 6 . From the simulation results, the baseline values for $\mathrm{B}_{1}$ and $\mathrm{C}_{\mathrm{RT}}$ are considered as the default values of 7 and 0.1 , respectively.

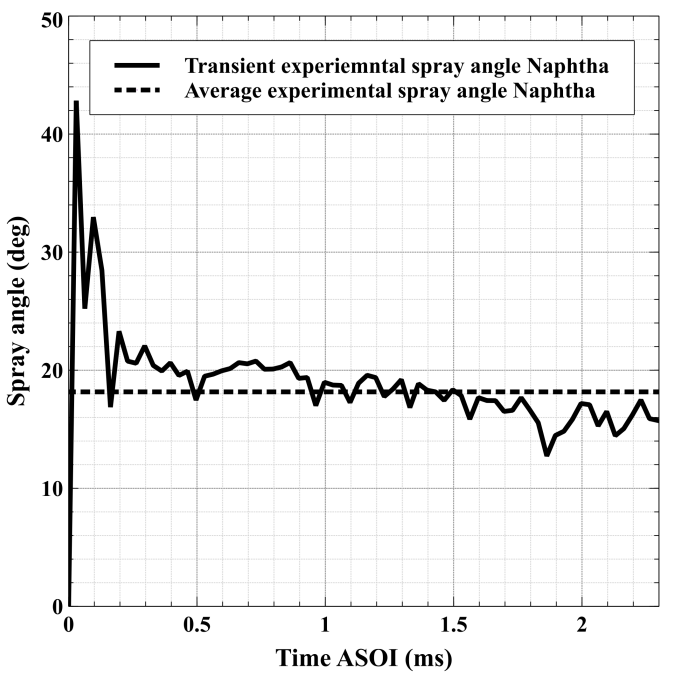

Figure 3. Transient experimental spray angle for high reactivity gasoline fuel. 

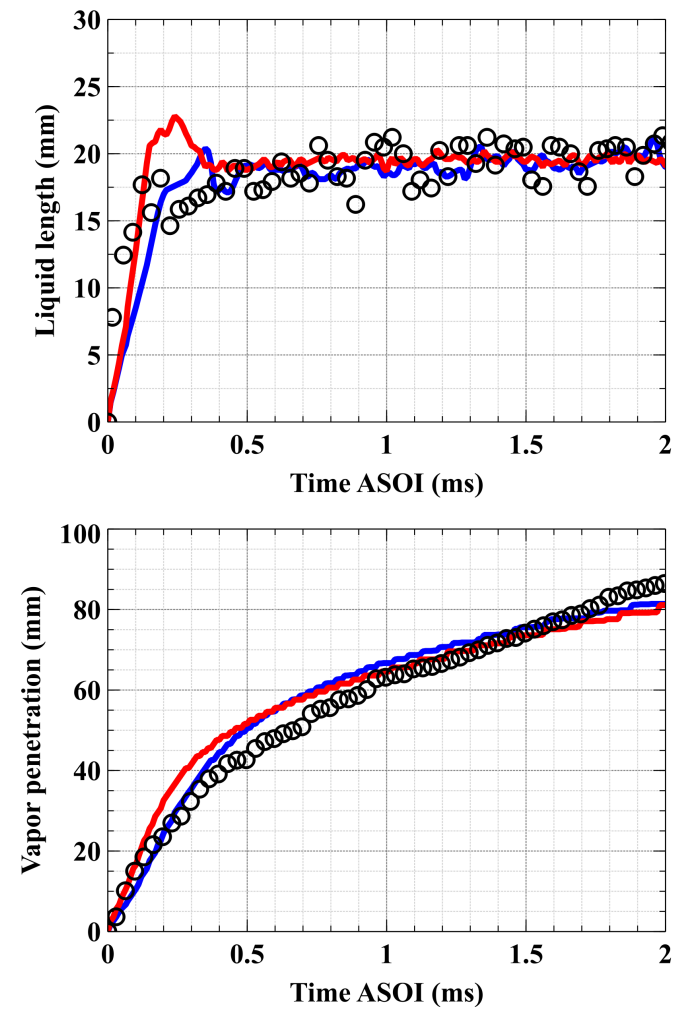

O MTU experiment

- Simulation - avg spray angle

Simulation - Transient spray angle lookup table

Figure 4. Effect of different spray angle inputs on liquid and vapor penetration of high reactivity gasoline fuel.

\section{Effect of droplet collision models}

Two different droplet collision models, O'Rourke [14] and no time counter (NTC) [15], were studied. Once a collision occurs, the outcomes are predicted as bouncing, stretching, reflexive separation, or coalescence [16]. Figure 7 shows the effect of different collision models on liquid and vapor penetrations of high reactivity gasoline fuel. Both methods show a negligible effect on the liquid and vapor penetrations. However, the NTC method involves stochastic subsampling of the parcels within each drop. This results in much faster collision calculations compared to O'Rourke method. In O'Rourke's method, the computational cost increases with the square of the number of parcels whereas, in the NTC method, the cost is linear. Furthermore, O'Rourke's method assumes that multiple collisions can occur between parcels and this process is governed by Poisson distribution. The Poisson distribution is incorrect unless collision has no consequences for the parcels. Since the collision changes the velocities, size and number of parcels, the method of repeated sampling used by the NTC method generates more accurate results. Therefore, the NTC collision model was considered to be the baseline model for further studies.
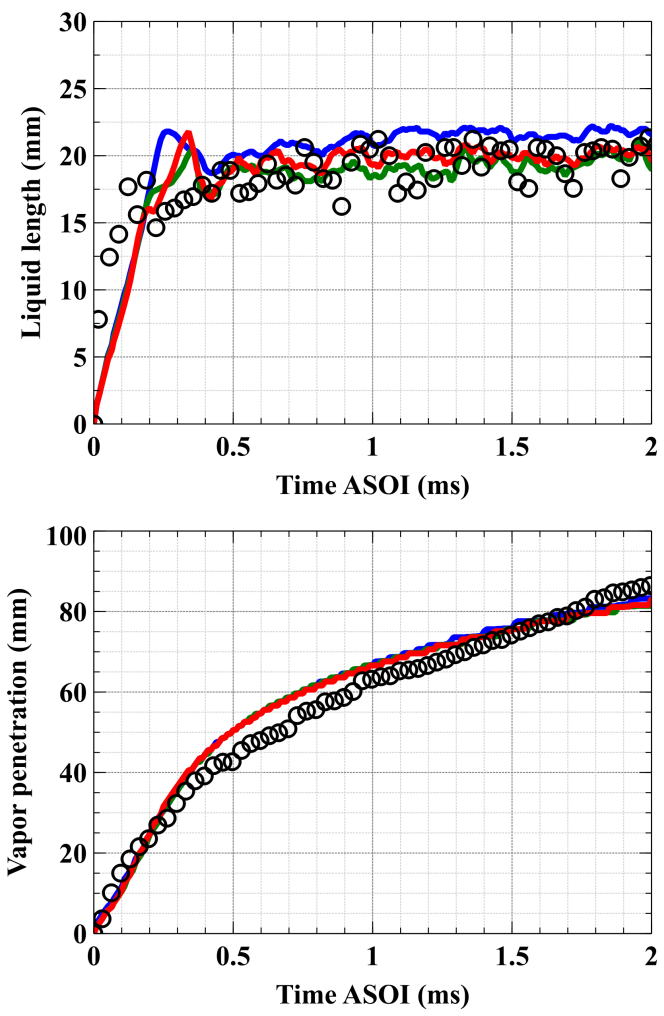

O MTU experiment $\longrightarrow$ Simulation - B1 $=5$ Simulation - B1=7 Simulation - B1=10

Figure 5. Effect of different $\mathrm{KH}$ model constant $\mathrm{B}_{1}$ on liquid and vapor penetration of high reactivity gasoline fuel.

\section{Effect of droplet evaporation models}

Two different droplet evaporation models, Frossling [17] and Chiang [18], have been tested. Figure 8 shows the effect of different droplet evaporation models on liquid and vapor penetrations of high reactivity gasoline fuel. The Chiang droplet evaporation model predicts longer liquid length compared to the Frossling evaporation model. However, a negligible change was observed in the vapor penetration length. The Chiang model includes the effect of convection, accounting for the effects of variable thermo-physical properties, transient heating and internal circulation of liquid, deceleration of the flow due to the drag of the droplet, boundary layer blowing and moving interface by introducing correction factors in the calculation of Sherwood and Nusselt numbers. Therefore, when using this model, the heat diffusion from gas phase to the droplet is lower than that of the Frossling model. Hence, Chiang model predicts a longer liquid length. Despite the detailed Chiang model, Frossling model captures enough evaporation physics to predict the spray characteristics on par with experiments. Therefore, the Frossling model was chosen to be the baseline evaporation model for further studies. 

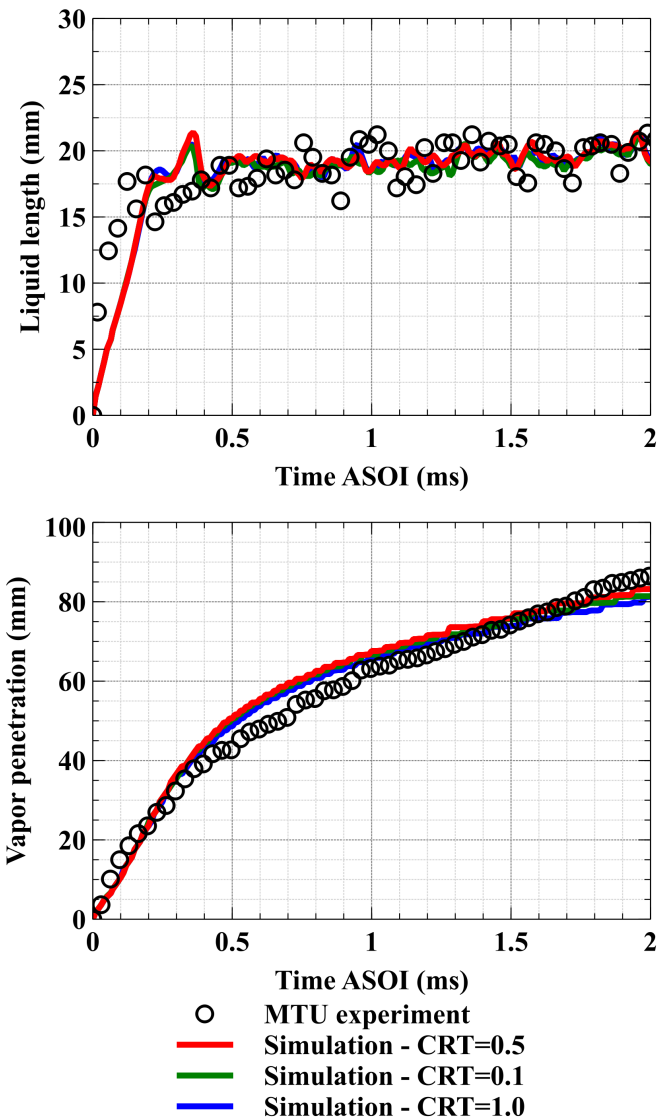

Figure 6. Effect of different RT model constant $\mathrm{C}_{\mathrm{RT}}$ on liquid and vapor penetration of high reactivity gasoline fuel.

\section{Spray Morphology}

The temporal evolution of fuel vapor mass fraction of high reactivity gasoline is shown in Fig. 9 for the baseline case. The experimental images shown is for single test realization. The simulation used transient spray angle, KH time constant, $\mathrm{B}_{1}$ as 7 , RT break-up model size constant, $\mathrm{C}_{\mathrm{RT}}$ as 0.1 , NTC collision model and Frossling droplet evaporation model. It can be observed that the simulation results qualitatively agree with the experimental data quite well at different timings.

\section{Effect of ambient temperature}

The effect of ambient temperature is studied by varying it at ambient pressures of $3 \mathrm{MPa}$ and $6 \mathrm{MPa}$ and fuel injection pressure of $150 \mathrm{MPa}$. Fig. 10 shows the liquid length comparison between experiment and simulation under ambient pressure of 3 and $6 \mathrm{MPa}$ at varying ambient temperature between $800-1200 \mathrm{~K}$. Only two temperature variants are studied in experiment under ambient pressure of $3 \mathrm{MPa}$ due to experimental constraint in achieving appropriate boundary conditions at such low ambient pressure. It can be seen that simulations capture the liquid length very well on par with the experiments. At ambient pressure of $6 \mathrm{MPa}$, the liquid length is almost insensitive to changes in the ambient temperature. It is interesting to note that the model is able to capture this trend and behavior very well. Fig. 11 shows the comparison of vapor penetration under varying temperature and ambient pressure of $3 \mathrm{MPa}$. At higher ambient temperatures, the vapor penetration length is longer due to lower ambient densities. It can be found that the model shows good prediction the vapor penetration lengths.
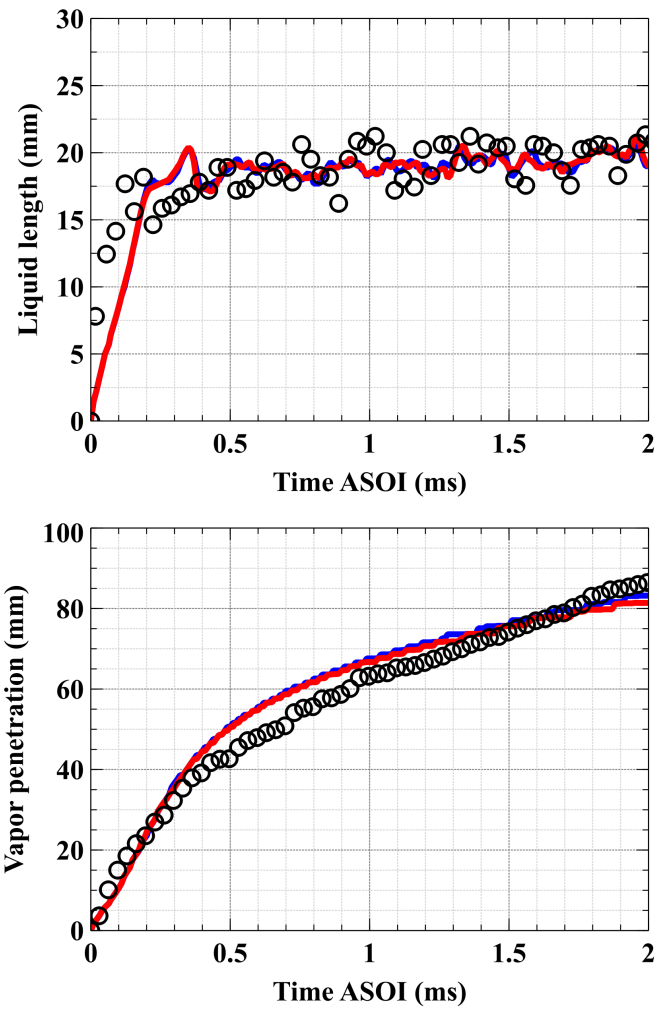

○ MTU experiment

Simulation - NTC collision model Simulation - O'Rourke collision model

Figure 7. Effect of different collision models on liquid and vapor penetration of high reactivity gasoline fuel.
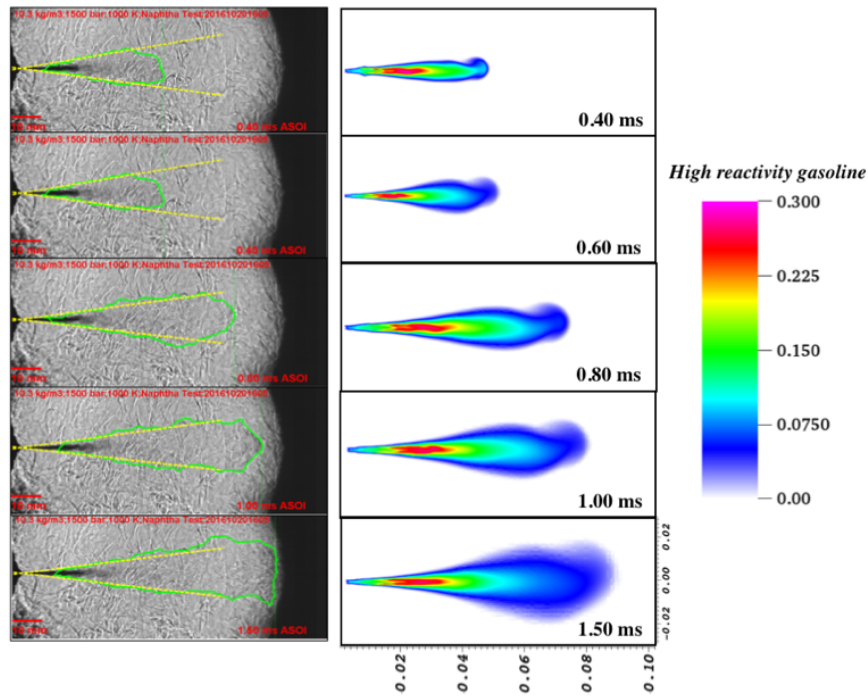

Figure 9. Temporal evolution of simulated fuel vapor mass fraction compared to experimental images. 

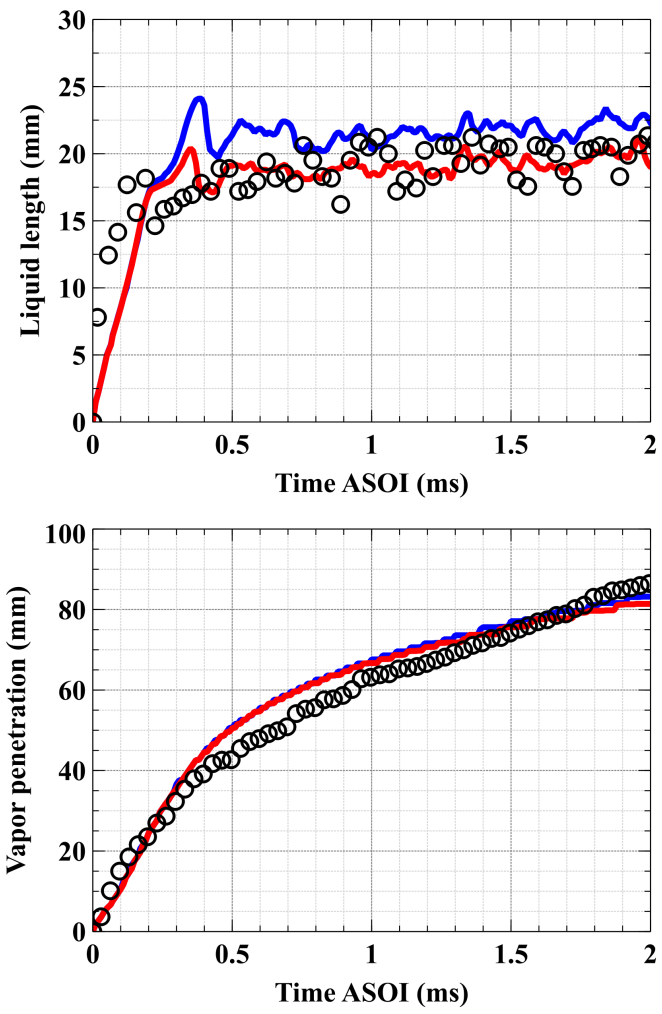

○ MTU experiment

- Simulation - Frossling evaporation model

- Simulation - Chiang evaporation model

Figure 8. Effect of different evaporation models on liquid and vapor penetration of high reactivity gasoline fuel.

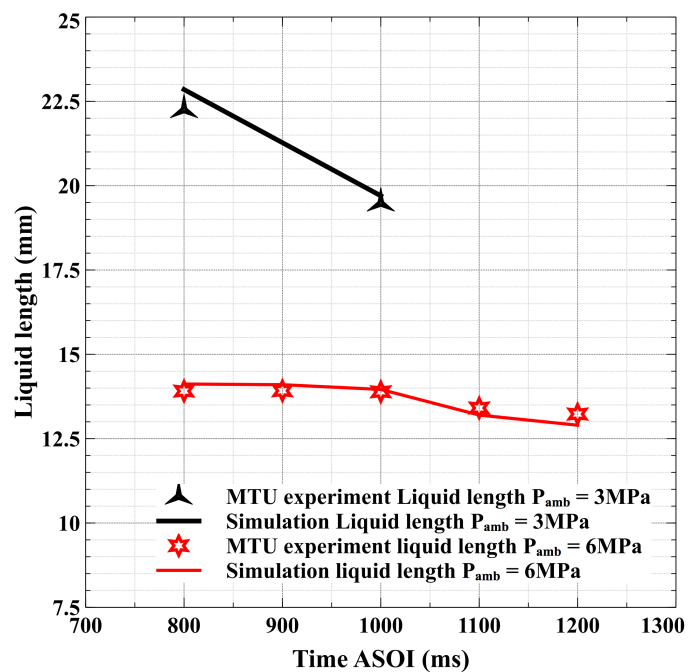

Figure 10. Comparison of experimental and simulation liquid length of high reactivity gasoline fuel under varying temperature at ambient pressure of 3 and $6 \mathrm{MPa}$

Page 6 of 8
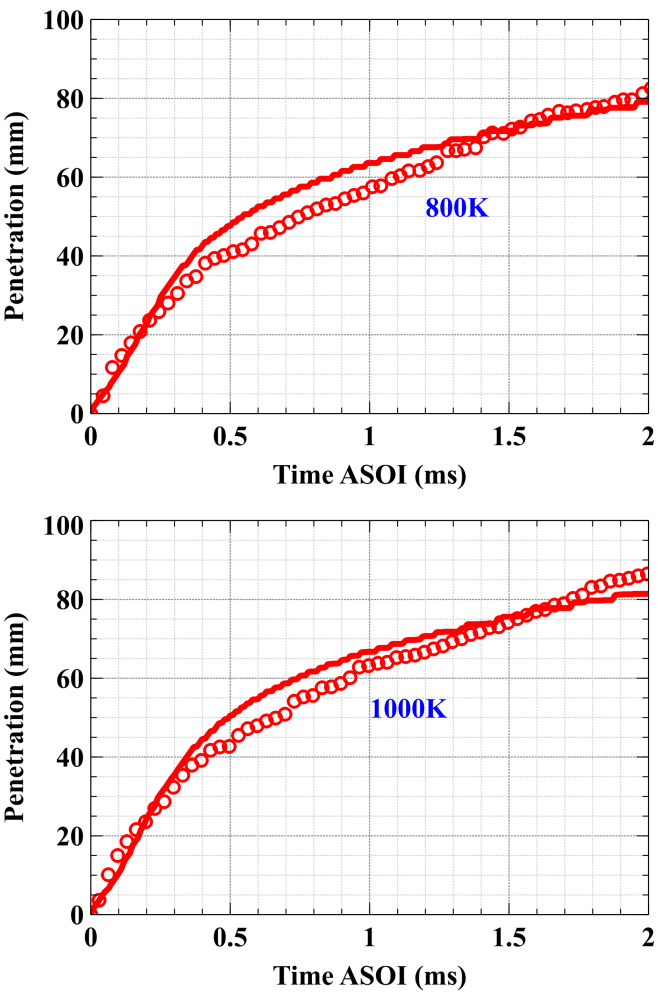

- MTU experiment Vapor penetration Simulation Vapor penetration

Figure 11. Comparison of experimental and simulation liquid length of high reactivity gasoline fuel under varying temperature and ambient pressure of $3 \mathrm{MPa}$.

\section{Simulation of reacting sprays}

Fig. 12 shows the comparison of predicted ignition delay of high reactivity gasoline fuel by two mechanisms with that of experiment in constant volume combustion chamber from MTU [3]. A wide range of temperatures (800-1200K) under ambient pressure of $6 \mathrm{MPa}$, injection pressure of $150 \mathrm{MPa}$ and $15 \%$ ambient oxygen were used for validation of the mechanisms. It is found that the PRF mechanism consistently under-predicts the ignition delay, whereas the new multicomponent surrogate (KMCS) mechanism predicts the ignition delay in good agreement with experiments. This shows that the new KMCS mechanism along with the thermo-physical properties used in the simulations performs well under heavy duty engine conditions.

In addition to the constant volume ignition delay validation, comparisons were made for the predicted heat release rate (HRR) by two mechanisms with that of experimental data. Fig. 13 shows the heat release rates of the simulations and experiment at ambient pressure of $6 \mathrm{MPa}$, injection pressure of $150 \mathrm{MPa}$ and $15 \%$ oxygen. The heat release rates are calculated using the following equation for both experiment and simulation

$$
\frac{d Q}{d t}=\frac{1}{\gamma-1} V \frac{d P}{d t}
$$

where, $\frac{d Q}{d t}$ is HRR, $\mathrm{P}$ is the pressure, $\mathrm{V}$ is the volume and $\gamma$ is the specific heat ratio. 


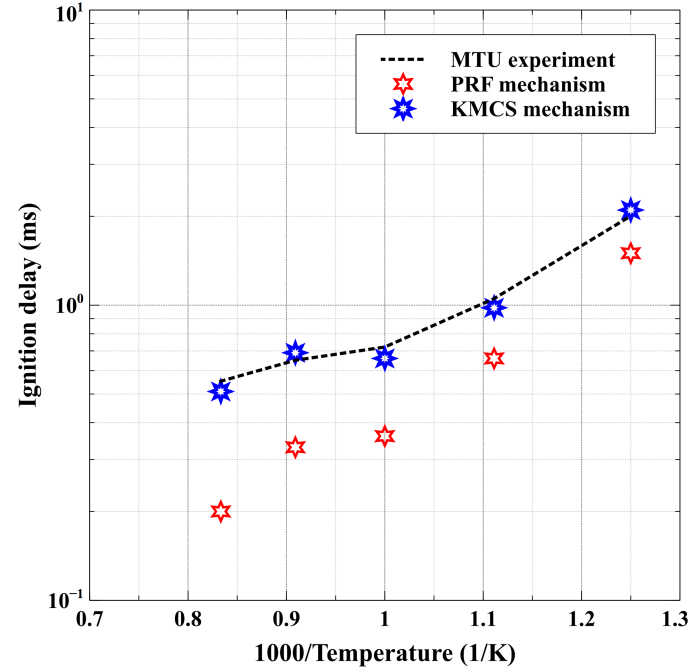

Figure 12. Comparisons between simulated and experimental ignition delay times of high reactivity gasoline for a wide range of temperatures at ambient pressure of $6 \mathrm{MPa}$, injection pressure of $150 \mathrm{MPa}$ and $15 \%$ ambient oxygen.

Fig. 13 shows that the start of ignition for PRF mechanism is advanced compared to that of new KMCS mechanism. The start of ignition predicted by new KMCS mechanism is close to that of the experimental data. Only a small difference was observed between the new KMCS mechanism and experimental peaks. This confirms that the new KMCS mechanism is reliable for predicting heat release rate of high gasoline reactivity fuel under heavy duty engine conditions.

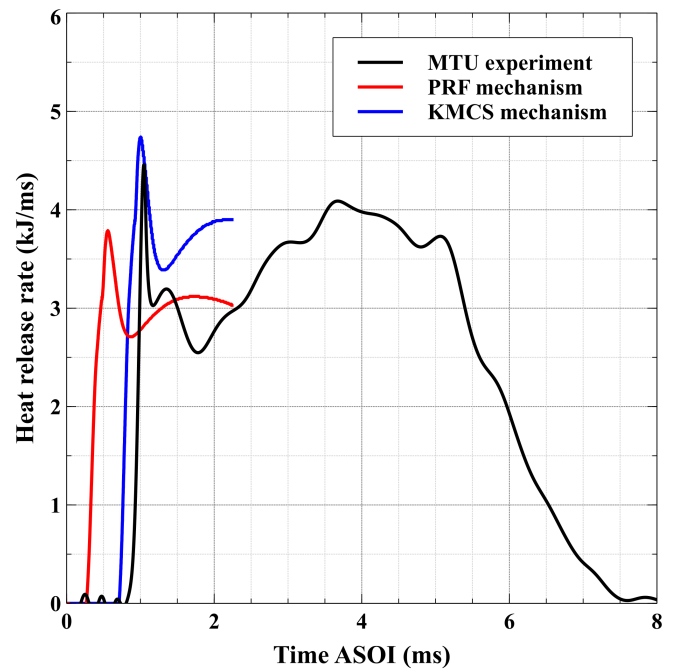

Figure 13. Comparisons between simulated and experimental heat release rates of high reactivity gasoline for ambient temperature of $1000 \mathrm{~K}$, ambient pressure of $6 \mathrm{MPa}$, injection pressure of $150 \mathrm{MPa}$ and $15 \%$ ambient oxygen.

\section{Summary/Conclusions}

Numerical simulations of high reactivity gasoline sprays under vaporizing and reactive condition in constant volume combustion chamber were performed in this study. The simulations show that the angle must be given as input over time using a lookup table to improve the fidelity of the predictions of CONVERGE. The effect of the KH-RT model constants was tested to identify proper baseline values. Furthermore, the effects of different sub-models on the liquid Page 7 of 8 and vapor penetrations of vaporizing sprays were investigated. From the simulation results, the baseline values of model constants and baseline sub-models were determined for vaporizing spray conditions. The following recommendations are derived for simulating high reactivity gasoline fuel

1. For the KH-RT model, the two major constants, $B_{1}$ and $\mathrm{C}_{\mathrm{RT}}$, are set as 7 and 0.1 , respectively.

2. The NTC collision model is preferred over O'Rourke model for computational cost consideration.

3. The Frossling droplet evaporation model yields better prediction than the Chiang model for droplet evaporation.

4. The new KMCS mechanism predicts both the ignition delay and heat release rate in good agreement with the experimental data compared to that of PRF mechanism.

\section{References}

[1] Zhang, Y., Kumar, P., Traver, M., Cleary, D. "Conventional and Low Temperature Combustion Using Naphtha Fuels in a Multi-Cylinder Heavy-Duty Diesel Engine." $S A E$ International Journal of Engines 9,1021-35,2016.

[2] Zhang, J., Tang, M., Menucci, T., Schmidt, H., Lee, S-Y., Naber1, J., et al. Experimental Investigation of Spray Characteristics of High Reactivity Gasoline and Diesel Fuel Using a Heavy-Duty Single-Hole Injector, Part II: NonReacting, Vaporizing Sprays. ILASS-Americas 29th Annu. Conf. Liq. At. Spray Syst., Atlanta, GA: 2017.

[3] Meng, T., Jiongxun, Z., Tyler, M., Henry, S., Jeffrey, N., Seong-Young, L., et al. Experimental spray ignition and soot forming characteristics of high reactivity gasoline and diesel fuel in a heavy-duty single-hole injector, 2017.

[4] Arcoumanis, C., Gavaises, M., French, B. "Effect of fuel injection process on the structure of diesel sprays." $S A E$ Paper, 1997.

Faeth, GM. "Mixing, transport and combustion in sprays." Progress in Energy and Combustion Science 13,293$345,1987$.

Chang, J., Kalghatgi, G., Amer, A., Viollet, Y. "Enabling high efficiency direct injection engine with naphtha fuel through partially premixed charge compression ignition combustion." SAE Technical Paper; 2012.

[7] Chang, J., Viollet, Y., Amer, A., Kalghatgi, G. "Fuel economy potential of partially premixed compression ignition (PPCI) combustion with naphtha fuel." SAE Technical Paper; 2013.

[9] Zhang, Y., Voice, A., Tzanetakis, T., Traver, M., Cleary, D. "An Evaluation of Combustion and Emissions Performance With Low Cetane Naphtha Fuels in a Multicylinder HeavyDuty Diesel Engine.” Journal of Engineering for Gas 
Turbines and Power 138,102805,2016.

[10] Reid, RC., Prausnitz, JM., Poling, BE., Prausnitz, JM., John Paul, O., Reid, RC. "The properties of gases and liquids" 5,1987 .

[11] An, Y., Li, X., Teng, S., Wang, K., Pei, Y., Qin, J., et al. "Development of a soot particle model with PAHs as precursors through simulations and experiments." Fuel $179,246-57,2016$.

[12] An, Y., Pei, Y., Qin, J., Zhao, H., Teng, S., Li, B., et al. "Development of a PAH (polycyclic aromatic hydrocarbon) formation model for gasoline surrogates and its application for GDI (gasoline direct injection) engine CFD (computational fluid dynamics) simulation." Energy 94,36779,2016 .

[13] Sarathy, SM., Kukkadapu, G., Mehl, M., Javed, T., Ahmed, A., Naser, N., et al. "Compositional effects on the ignition of FACE gasolines." Combustion and Flame 169,171-93,2016. doi:10.1016/j.combustflame.2016.04.010.

[14] O'Rourke, PJ. "Collective drop effects on vaporizing liquid sprays.” Los Alamos National Lab., NM (USA); 1981.

[15] Schmidt, DP., Rutland, CJ. "A new droplet collision algorithm." Journal of Computational Physics 164,6280,2000 .

[16] Post, SL., Abraham, J. "Modeling the outcome of drop-drop collisions in Diesel sprays." International Journal of Multiphase Flow 28,997-1019,2002.

[17] Amsden, AA., O'rourke, PJ., Butler, TD. "KIVA-II: A computer program for chemically reactive flows with sprays." Los Alamos National Lab., NM (USA); 1989.

[18] Chiang, CH., Raju, MS., Sirignano, WA. "Numerical analysis of convecting, vaporizing fuel droplet with variable properties." International Journal of Heat and Mass Transfer 35,1307-24,1992.

\section{Contact Information}

Dr. Balaji Mohan

Post-doctoral research fellow Clean Combustion Research Centre (CCRC)

King Abdullah University of Science and Technology (KAUST)

Thuwal - 23955-66900, Saudi Arabia

balaji.mohan@,kaust.edu.sa

Phone no - +966 544701875

\section{Acknowledgments}

This work was sponsored by the Saudi Aramco under the FUELCOM II program and by King Abdullah University of Science and Technology. The computational simulations utilized the clusters at

Page 8 of 8
KAUST Supercomputing Laboratory and IT Research Computing. The author thanks Convergent Science Inc. for providing CONVERGE license. 